Tohoku J. exp. Med., 1983, 141, Suppl., 119-123

\title{
Studies on the Classification of Diabetes Mellitus Diagnosed before the Age of 30 in Japan
}

\author{
Yukimasa Hirata and NaOko NagaI \\ Diabetes Center, Tokyo Women's Medical College, Tokyo \\ 162, Japan
}

\begin{abstract}
Hirata, Y. and Nagal, N. Studies on the Classification of Diabetes Mellitus Diagnosed before the Age of 30 in Japan. Tohoku J. exp. Med., 1983, 141, Suppl., 119-123 - Since 1976, 551 patients with diabetes discovered before the age of 30 have been treated in the Diabetes Center of Tokyo Women's Medical College. Among them, 198 were classified as insulin-dependent diabetes (IDDM), 237 as noninsulin-dependent diabetes (NIDDM), 12 were unclassified, and four were classified as other typers. In patients with IDDM, the number of males was lower than that of females, 80 and 118 respectively. The number of patients discovered with NIDDM over the age of 25 was much higher in males than in females. To study the influencce of family history, 148 probands were selected from the 551 diabetics according to age at onset of diabetes (under 20 years old) and present age (between 20 and 40 years old). At the interview, the number of first-degree relatives and the number of diabetics among them were recorded. Six out of 75 probands $(8 \%)$ with IDDM had positive family histories for NIDDM and two of the $75(3 \%)$ had positive family histories for IDDM, although 39 out of 73 probands $(53 \%)$ with NIDDM had positive family histories for NIDDM alone. There was only a slight differene in the course of retinopathy between patients with IDDM and NIDDM. classifiaction of diabetes; heredity of diabetes; insulin-dependent diabetes; retionopathy
\end{abstract}

It has been thought for a long time that the prevalence of insulin-dependent diabetes mellitus (IDDM) is much lower among the Japanese than Caucasians. Only 51 diabetic children had been reporrted in Japan before 1945, and only eight diabetic children attended the first summer camp which was started for diabetic children in 1963. There was only one summer camp in Japan as recently as 1969.

Recently, the records of young patients whose diabetes was diagnosed before the age of 30 have been collected at the Diabetes Center of Tokyo Women's Medical College. Using these records, the classification of the type of diabetes, prevalence of positive family history of diabetes, and also the prevalence of diabetic retinopathy are analysed.

The current mailing address: Diabetes Center, Tokyo Women's Medical College, 10 Kawada-cho, Shinjukuku-ku, Tokyo 162, Japan. 


\section{Subjects and Methods}

From January 1976 to December 1981, 551 patients with diabetes diagnosed before the age of 30 were treated in the Diabetes Center of Tokyo Women's Medical College.

Classification of the type of diabetes in these patients was performed according to their tedency suffer from ketosis, which was the most important factor in the differentiation of IDDM from NIDDM, the mode of onset of the disease and the dose of insulin required daily. Family histories of all 551 patients were collected by questioning at the first visit and comfirmed at an interview by one of authors. At the interview, the total number of first degree relatives and the number of diabetics among them were recorded, and the type of diabetes in each of the diabetic relatives was esimated.

To compare the differences in family histories between patients with IDDM and with NIDDM, we selected probands who met four requirements : 1) their diabetes was found before the age of 20,2 ) their age in 1982 was between 20 and 40 years, 3) they had a duration of diabetes of three years or more, 4) and if two or more diabetics came from one family, the first patient to visit the Center was picked as the proband. Among 551 patients with diabetes, 148 probands were selected by those procedures and analyzed. Also, 100 nondiabetic patients visiting the Diabetes Center in 1982 and aged between 20 and 40 years were picked out at random as subjects of the control group.

To compare characteristics of retinopathy between IDDM and NIDDM in young people, prospective follow-up studies must be done regularly. Our retrospective analysis of retinopathy seems insufficient for this purpose, and therefore, only the results of the ophthalmoscopic examination performed in 1982 in the probands mentioned above are reported in this paper.

\section{REsults}

\section{Types of diabetes and Age at Onset}

Of 551 patients, 198 were classified IDDM, 337 as NIDDM, 12 were unclassified, and four were classified as other types. The onset of IDDM was much earlier than that of NIDDM as shown in Table 1. Diabetes occurred before 15 yrs of age in 119 patients out of 198 patients with IDDM, although diabetes was discovered in only 17 patients under $15 \mathrm{yrs}$ of age of the 337 patients with NIDDM. After the age of 15 , the number of patients with NIDDM increased significantly.

\section{Sex distribution}

The sex distribution in Japan between IDDM and NIDDM is worthy of note. In patients with IDDM, the number of males and the number of females were, 80 and 118 respectively. In patients with NIDDM, the number of males was almost the same as that of females, 175 and 162 respectively, although the number of patients with NIDDM diagnosed over the 25 age of was much higher in males than females (Table 1).

\section{Family history of diabetes}

The percentage of patients with diabetic first-degree rmlatives was much lower in the 198 patients with IDDM than in the 337 patients with NIDDM, 10. $6 \%$ and $45.1 \%$ respectively. 
TABLE. 1. Sex and age at onset of diabetes in 551 patients (Tokye Women's Medical College, 1971-1981)

\begin{tabular}{ccccc}
\hline Age at onset & \multicolumn{2}{c}{ IDDM* $^{*}$} & \multicolumn{2}{c}{ NIDDM $\dagger$} \\
\cline { 2 - 5 } of diabetes & Male & Female & Male & Female \\
$0-9$ & 25 & 36 & 1 & 0 \\
$10-14$ & 27 & 31 & 7 & 9 \\
$15-19$ & 11 & 18 & 226 & 37 \\
$20-24$ & 9 & 16 & 39 & 46 \\
$25-29$ & 8 & 17 & 102 & 70 \\
Total & 80 & 118 & 175 & 162 \\
\hline
\end{tabular}

* IDDM : Insulin-dependent diabetes mellitus.

$\uparrow$ NIDDM : Non-insulin-dependent diabetes mellitus.

TABLE. 2. Family histories of the selected 148 probands*

\begin{tabular}{cccc}
\hline & IDDM & NIDDM & Nondiabetic \\
\hline $\begin{array}{c}\text { Number of probands } \\
\text { (mean present age) }\end{array}$ & 75 & 73 & 100 \\
$\begin{array}{c}\text { Positive family } \\
\text { history }\end{array}$ & $8 / 75=11 \%$ & $39 / 73=53 \%$ & $6 / 100=6 \%$ \\
Family history of & & & \\
IDDM & $2 / 75=3 \%$ & $39 / 73=53 \%$ & $0 \%$ \\
NIDDM & $6 / 75=8 \%$ & & $6 / 100=6 \%$ \\
$\begin{array}{c}\text { Parents } \\
\text { diabetic/total }\end{array}$ & $6 / 150=4 \%$ & $39 / 146=27 \%$ & $6 / 200=3 \%$ \\
$\begin{array}{c}\text { Siblings } \\
\text { diabetic/total }\end{array}$ & $2 / 99=2 \%$ & $15 / 150=10 \%$ & $0 \%$ \\
$\begin{array}{c}\text { Offspring } \\
\text { diabetic/total }\end{array}$ & $0 / 7=0 \%$ & $0 / 21=0 \%$ & $0 \%$ \\
\hline
\end{tabular}

* Probands selected from 551 diabetics listed in Table 2.1 as follows : onset of diabetes before the age of 20 years, present age between 20and 40-years old, and a duration of diabetes of three years or more.

The interviews disclosed a significant difference in family history of diabetes between the 148 probands selected as described above and the 100 non-diabetics. The percentage of probands who had diabetic firstdegree relatives was $11 \%$ among the 75 probands with IDDM, 53\% among 73 probands with NIDDM, and $6 \%$ among the 100 controls. Six of the 75 probands with IDDM had parents with NIDDM and two had siblings with IDDM. Thirty-six of the 73 probands with NIDDM had parents with NIDDM and 12 had siblings with NIDDM. Nine of the 12 also had diabetic parents.

Among 150 parents of the 77 probands with IDDM, there were six patients with NIDDM ( $4 \%$ ), and among 99 siblings of those probands, two with IDDM were found $(2 \%)$. Among 146 parents of the 73 probands with NIDDM there were 39 with NIDDM $(27 \%)$, and $15(10 \%)$ out of 150 siblings were diagnosed as 
NIDDM (10\%). There were no diabetic offspring in either goroup until 1982. Among 200 parnents of the centrol group, six (3\%) were suffering from NIDDM, and there werm no diabetic siblings (Table 2).

\section{Diabetic retinopathy}

From January to July 1982, ophthalmoscopic examinations were performed on 139 of the 148 probands described above. Although diabetic retinopathy appeared earlier in patients with NIDDM than in those with IDDM within 10 years of the estimated onset of diabetes, 10 years after the onset of diabetes, retinopathy seemed to progress faster in patients with IDDM than those with NIDDM (Table 3).

TABLE. 3. Retinopathy examined in 139 (75 with IDDM and 64 with NIDDM) of the 148 probands* in 1982

\begin{tabular}{|c|c|c|c|c|c|c|c|c|}
\hline \multirow{3}{*}{$\begin{array}{l}\text { Estimated duration } \\
\text { of diabetes (years) }\end{array}$} & \multicolumn{8}{|c|}{ Retinopathy } \\
\hline & \multicolumn{4}{|c|}{ IDDM } & \multicolumn{4}{|c|}{ NIDDM } \\
\hline & neg & $\mathrm{BR}$ & PR & total & neg & $\mathrm{BR}$ & PR & total \\
\hline $0-4$ & 2 & 0 & 0 & 2 & 11 & 1 & 0 & 12 \\
\hline $5-9$ & 4 & 3 & 0 & 7 & 16 & 5 & 3 & 24 \\
\hline $10-14$ & 6 & 28 & 2 & 36 & 4 & 8 & 4 & 16 \\
\hline $15-19$ & 2 & 8 & 6 & 16 & 2 & 4 & 1 & 7 \\
\hline 20 & 1 & 9 & 4 & 14 & 0 & & 2 & 7 \\
\hline Total & & & & 75 & & & & 64 \\
\hline
\end{tabular}

* Same as Table 2. neg, negative; BR, background retinopathy; $\mathrm{PR}$, proliferative retinopathy,

\section{Discussion}

There has been only one report concerning family histories of patients with IDDM in Japan. Kuzuya and Matsuda ${ }^{12}$ reported that the frequency of positive family histories of diabetes in first-degree relatives was $24 \%(13 / 55)$ in IDDM and $44 \%(281 / 631)$ in NIDDM $(p<0.01$ versus IDDM). In their report 720 patients were subjected to an analysis of family history. Because the peak of onset in those diabetics was between 40 and 49 years old, the number of patients whose diabetes had been discovered before the age of 20 was only 22 .

Even in our present study the number of patients diagnosed as diabetic before the age of 20 was only 233 including 148 patients with IDDM.

To compare differences in family histoy between IDDM and NIDDM subjects, 148 probands were selected as mentioned above. Although in 75 probands with IDDM the onset of the disease was relatively early compared to the 73 probands with NIDDM, the mean present age of the IDDM group was almost the same as that of the NIDDM group, i.e., 26.0 and 26.7 years respectively. Positive family 
histories for diabetes were much less frequent in the IDDM group. Among the 75 probands with IDDM, six had parents with NIDDM $(8 \%)$, while 6 subjects out of 100 non-diabetics had parents with NIDDM. MacDonald ${ }^{2)}$ reported an equal incidence of adult-onset diabetes (NIDDM) among the offspring of juvenile diabetics (IDDM) and nondiabetics, and our results confirm his report.

Gamble $^{3)}$ and Walker and Cudworth ${ }^{4)}$ reported that 184 families out of 4869 families of children with diabetes in England had indicated the presence of two or more affected siblings, that is $3.8 \%$ of probands with IDDM had diabetic siblings. In our stuny, two out of 75 probands with IDDM had siblings with IDDM ( $3 \%)$. That is, there was no difference between the frequencies of England and Japan. Heredity of diabetes in Japanese in whom NIDDM was discovered before the age of 30 was as strong as that already reported in Caucasians.

At least before 1982, retinopathy in both young groups of IDDM and NIDDM in Japan seemed to follow a progressive course to the proliferative stage. Because of the uncertain onset of NIDDM, proliferative retinopathy was found in some cases even 10 years after the estimated onset of NIDDM.

\section{References}

1) Kuzuya, T. \& Matsuda, A. (1982) Family histories of diabetes among Japanese patients with type 1 (insulin-dependent) and type 2 (non-insulin-dependent) diabetes. Diabetologia, 22, 372-374.

2) MacDonald, M.J. (1974) Equal ineidence of adult-onset diabetes among ancestors of juvenile diabetics and nondiabetics. Diabetologia, 10, 767-7736

3) Gamble, D.R. (1980) An epidemiological study of childhood diabetes affecting two or more siblings. Diabetologia, 19, 341-344.

4) Walker, A. \& Cudworth, A.G. (1980) Type 1 (insulin-dependent) diabetic multiplex families. Mode of genetic transmission. Diabetes, 29, 1036-1039. 